\title{
Sosialisasi Pemanfaatan Caklingking Sebagai Salah Satu Media Pembelajaran Siswa SD
}

\author{
Eka R. Kurniasi ${ }^{1 *}$, Hevitria ${ }^{2}$, S. Pitriyana ${ }^{2}$, M. Fuziani ${ }^{1}$, Wulandari ${ }^{1}$, F. Alghadari ${ }^{3}$ \\ ${ }^{1}$ Pendidikan Matematika, FKIP, Universitas Muhammadiyah Bangka Belitung \\ ${ }^{2}$ Pendidikan Guru Sekolah Dasar,FKIP, Universitas Muhammadiyah Bangka Belitung \\ ${ }^{3}$ Pendidikan Matematika, STKIP Kusuma Negara \\ *eka.rachmakurniasi@stkipmbb.ac.id
}

\begin{abstract}
Abstrak
Caklingking merupakan salah satu permainan tradisional yang dulu banyak dimainkan. Biasanya caklingking dimainkan bersama-sama dan menggunakan batu yang dibentuk untuk dimainkan. Berdasarkan masalah di lapangan, bahwa siswa tidak lagi memainkan caklingking dalam keseharian. Selain itu siswa tidak mengetahui bahwa caklingking dapat menjadi media belajar matematika. Karena masalah tersebut makan perlu sosialisasi pemanfaatan caklingking dalam pembelajaran siswa SD dan penggunaan permainan ini dalam keseharian. Tujuan pengabdian ini adalah sosialisasi pemanfaatan caklingking dalam pembelajaran siswa SD dan penggunaan permainan ini dalam keseharian. Metode pelaksanaan yang digunakan yaitu memberikan sosialisasi langsung kepada para siswa-siswa pengetahuan tentang pemanfataan caklingking. Kegiatan ini diikuti sebanyak 20 orang siswa SDN 14 Pangkalpinang. Kegiatan Sosialisasi ini telah sukses dilaksanakan.
\end{abstract}

Kata kunci: caklingking, media, pembelajaran SD, siswa.

\section{PENDAHULUAN}

Permainan tradisional merupakan permainan yang erat kaitannya dengan tradisi masyarakat di suatu tempat. Salah satu permainan tradisional yaitu Caklingking (Nurdiani, 2020; Yosinta, Nasirun \& Syam, 2016; Hasyim \& Putri, 2017), dan egrang batok (Andrian \& Ehan, 2017; Utami, 2021; Handoko \& Gumantan, 2021; Apriyono dkk. , 2019). Caklingking merupakan salah satu permainan tradisional yang dulu banyak dimainkan di Bangka (Yosinta, Nasirun \& Syam, 2016; Hasyim \& Putri, 2017). Biasanya caklingking dimainkan bersama-sama dan menggunakan batu yang dibentuk untuk dimainkan. Nurdiani (2020) menyatakan permainan caklingking ini memiliki nilai-nilai tertentu bagi pertumbuhan dan perkembangan anak-anak. Permainan Caklingking ini dimainkan dengan cara membuat bentukbentuk yang terdiri dari beberapa bidang datar yang kemudian digambarkan pada suatu tempat (Syaripuddin, 2019). Pola caklingking ini seperti kotak, memanjang persegi panjang, dan ada juga bentuknya rok dan bagian bawah biasanya diberi tangga. Nurdiani (2020) juga menyatakan bahwa jika dilihat dari bentuknya, maka permainan ini memiliki hubungan erat dengan matematika terutama dari sisi geometri, karena bentuk-bentuk bidang datar tersebut dikenal sebagai bangun datar dalam pembelajaran matematika.

Permainan tradisional seperti tersebut bisa menjadi bahan untuk menunjang pembelajaran (Nurhayati, 2012). Permainan tradisional edukatif merupakan salah satu alternatif yang dapat diterapkan dalam pembelajaran di sekolah dasar 
khususnya pembelajaran matematika, sehingga selain siswa dapatmengenal dan melestarikan budaya, diharapkan hasil belajar dan aktivitas siswa juga optimal. Pada kenyataannya, permainan tradisional lebih banyak dimainkan siswa di luar ruang lingkup pembelajaran di sekolah (Fajrin, 2015). Siswa lebih banyak memainkannya ketika mereka sedang dalam waktu istirahat diantara dua jam pelajaran. Fakta ini menunjukan bahwa permainan tradisional benar-benar dimainkan tidak dalam konteks pembelajaran dan tidak dimanfaatkan untuk penerapan konsep materi. Di sisi lain, kadang pembelajaran yang dilakukan masih bersifat textbook. Mungkin ada guru yang paham bahwa pembelajaran matematika juga bisa melalui permainan seperti Caklingking, tetapi tuntutan kurikulum dan capaian pembelajaran masih menjadi fokus pertimbangan paling utama sebelum membuat keputusan. Lebih lanjut, permainan tradisional dibawakan dalam pembelajaran matematika di Indonesia tentu ketika lembaga pendidikan keguruan sudah mengenalkanetnomatematika, sementara berdasarkan penelusuran bahwa tulisan etnomatematika pertama di Indonesia terbit tahun 2008 (lihat Kadir, 2008), dan ini kontras dengan angkatan kerja guru di sekolah sekarang. Oleh karena itu, perlu sosialisasi pemanfaatan caklingking dan egrang batok dalam pembelajaran siswa SD. Kegiatannya dilakukan di SDN 14 Pangkalpinang dalam rangka pengabdian kepada masyarakat.

Kegiatan pendampingan permainan tradisional edukatif ini dilakukan supaya dapat membangunperhatian pada keterkaitan antara permainan tradisional yang diwariskan dengan pembelajaran matematika, memotivasi siswa bahwa ruang lingkup pembelajaran matematika tidak terbatas pada textbook dan angka-angka numerik, serta menghadirkan potensi sebagai penunjang kegiatan pembelajaran guru. Melalui permainan tradisional edukatif ini, siswa juga dapat menemukan pengetahuan dan pengalamannya sendiri secara menyenangkan (Ulya, 2017). Siswa dapat mengenal dan mempelajari kekayaan budaya yang kita miliki melalui berbagai permainan tradisional yang sudah punah pada saat ini karena teralihkan oleh gadget (Zayyadi, 2019). Pada era revolusi industri 4.0 ini, teknologi dan komunikasi berkembang sangat pesat. Usaha untuk tetap menyeimbangkan rasa kebangsaan dan cinta tanah air pada siswa salah satunya dapat melalui permainan tradisional. Selain menyenangkan juga penuh akan makna pembelajaran di dalamnya.

\section{METODE PELAKSANAAN}

Kegiatan pelaksanaan pengabdian kepada masyarakat ini dilaksanakan pada bulan Juli 2021 yang berlokasi di SD Negeri 14 Pangkalpinang kelurahan Ketapang, kecamatan Pangkal Balam, kota Pangkalpinang. Peserta pada kegiatan ini diikuti sebanyak 20 siswa/siswi. Pelaksanaannya dilakukandengan sosialisasi kepada siswa tersebut. Adapun sosialisasi secara tatap muka, dibagi menjadi dua bagian. Pertama pemberian materi kepada siswa tentang pemanfaatan caklingking dalam pembelajaran. Kedua Siswa mencoba permainan caklingking secara langsung pada saat jam pelajaran sekolah.

Pemaparan materi dan pemanfaatan permainan caklingking diberikan langsung oleh tim pengabdian kepadaguru serta siswa/siswi yang adadi sekolah. Pemaparan materi dan pemanfaatan permainan caklingking langsung dilakukan berupa ceramah, dilanjutkan dengan praktik langsung bagaimana cara memainkan 
permainan caklingking. Siswa dapat melihat langsung cara memainkan caklingking yang ditampilkan oleh tim pengabdian. Selanjutnya siswa akan diberikan kesempatan memainkan permainan caklingling agar paham saat memainkannya. Kegiatan diakhiri dengan lomba, tanya jawab, dan foto bersama dengan siswa-siswi yang hadir pada acara tersebut.

\section{HASIL DAN PEMBAHASAN}

Permainan Caklingking merupakan salah satu jenis permainan tradisional yang menggunakan benda dan hitungan serta adanya kesepakatan peraturan-peraturan yang harus dipatuhi oleh pemain berkaitandengan pelaksanaannya. Permainan caklingking tersebut dapat mengembangkan kemampuan kognitif dan kedisiplinan. Aspek perkembangan yang harus dikembangkan pada siswa sekolah dasar dapat menggunakan permainan tradisional caklingking. Pada permainan caklingking ini guru menyediakan gambar menggunakan cat warna-warni sesuai dengan tema yang telah direncanakan dan menambah kegiatan menyanyi, meniru gerak dan lain-lain. Gambar yang disediakan dari tim pengabdian tertera di halaman sekolah, sehingga gambar pada permainan caklingking ini dapat menambah indah suasana halaman sekolah karena menggunakan warna-warni yang cerah.

Kegiatan Sosialisasi ini telah sukses dilaksanakan. siswa memahami bahwa caklingking tidak hanya sekedar permainan, namun ada unsur pembelajaran didalamnya yang mengaitkan antara warisan budaya dan pembelajaran matematika. Selain itu permainan tradisional seperti caklingking ini juga sangat perlu dilestarikan sebagai salah satu ciri budaya daerah setempat. Dalam pelaksanaan kegiatan sosialisasi, hanya siswa yang diikutsertakan dalam permainan, setelah kegiatan selesai, maka gambar permainan pada lantai ini semoga bermanfaat bagi siswa lain jika mereka ada kesempatanuntuk memainkannya. Gambar permainan pada lantai sedang dimainkan oleh siswa dapat dilihat pada Gambar 1.

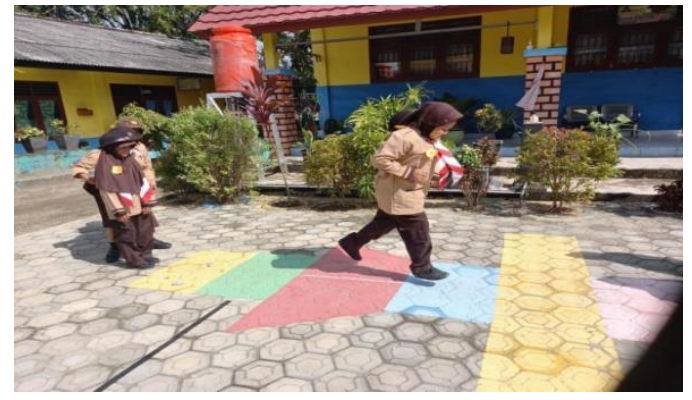

(a)

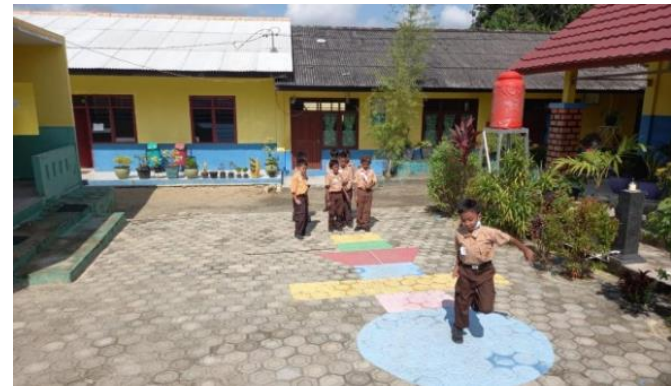

(b)

Gambar 1. Siswa SD memainkan Caklingking

Permainan tradisional ini juga bisa mengalihkan perhatian siswa dari rutinitas penggunaan smartphone. Jika bermain smartphone dapat merusak mata makapermainan ini malah menumbuhkan psikomotorik siswa dengan melakukan pergerakan aktif, melatih otot, dan bersosialisasi dengan teman-teman. Budaya sosial siswa dibentuk melalui permainan tradisional ini karena memainkannya tidak dilakukan mandiri melainkan harus adalawan main meskipun bermainnya 
secara bergantian. Efendi (2015) menerangkan bahwa permainan tradisional mampu untuk menstimulasi perkembangan motorik anak. Hal ini disebabkan karena dalam pelaksanaan permainan tradional lebih banyak melibatkan banyak kemampuan seperti berjalan, melompat, tarik menarik, melempar, jongkok, menendang, bahkan berlari. Permainan tradisional caklingking ini banyak memberikan siswa menjadi bersemangat, selain bermain tapi mereka juga bisa sambil belajar terutama dalam berkonsentrasi. Kemudian, salah satu manfaat bermain caklinking adalah bisa bersosialisasi dengan teman-teman. Berinteraksi dengan teman sebaya sangat baik dilakukan oleh anak usia dini. Banyak manfaat yang akan diperoleh baik untuk melatih kecerdaasan maupun kemampuan sosial anak. Permainan tradisional juga mempererat persatuan dan menjaga warisan budaya.

Penting bagi warga Negara memahami nilai budaya daerah di mana itu dapat diintegrasikan melalui pelaksanaan pendidikan, seperti melalui proses pembelajaran. Pembelajaran yang dilaksanakan disekolah memuat beberapa mata pelajaran salah satunya adalah mata pelajaran Matematika. Pembelajaran Matematika adalah proses pemberian pengalaman belajar kepada peserta didik melalui serangkaian kegiatan yang terencana sehingga peserta didik memperoleh kompetensi tentang bahan matematika yang dipelajari (Muhsetyo, Krisnadi \& Wahyuningrum, 2014). Ini sesuai dengan tujuan pembelajaran Matematika di sekolah dasar agar siswa mampu dan terampil menggunakan matematika. Selain itu juga, dengan pembelajaran matematika dapat memberikan tekanan penataran nalar dalam penerapan matematika (Susanto, 2013). Mata pelajaran matematika di sekolah dasar meliputi aspekbilangan,geometri, dan pengolahan data dengan cakupan geometri antara lain bangun dua dimensi, tigadimensi, transformasi dan simetri,lokasi dan susunan berkaitan dengan koordinat (Kurniawan, 2016). Permainan engklek yang menggunakan kotak berbentuk persegi dan persegi panjang didalamnya berisi muatan geometri. Guru bisa memanfaatkan unsur tersebut ketika sedang menyampaikan bentuk model bidang datar.

Keberadaan gambar permainan pada lantai itu bisa bermanfaat untuk menambah perbendaharaan cerita spontan guru dan sekaligus menjadi variasi model bidang datar yang disampaikan kepada siswa. Pembelajaran matematika yang tidak bervariasi menjadikan peserta didik bosan (Misyanto, 2016), sehingga untuk menghilangkan kebosanannya maka peserta didik lebih suka bermain dengan temannya (Ulya, 2017). Hambatan dalam pembelajaran matematika tersebut dapat dijadikan bahan evaluasi guru untuk memperbaiki proses pembelajaran. Oleh karena peserta didik menyukai bermain, maka guru dapat menyisipkan permainan dalam proses pembelajaran. Namun, permainan tersebut hendaknya mampu membuat peserta didik belajar dengan pengalamannya sendiri. Selain permainan yang digunakan dalam pembelajaran mampu membuat peserta didik belajar dengan pengalamannya sendiri, permainan juga dapat membuat peserta didik mempelajari kekayaan budaya yang dimiliki. Permainan tradisional dapat dijadikan sebagai alternatif solusi tersebut, sehingga selain peserta didik dapat mengenal dan melestarikan budaya, diharapkan hasil belajar peserta didik juga optimal. Hal Ini sesuai dengan kutipan dalam referensi Ulya (2017) bahwa melalui permainan tradisional dapat meningkatkan hasil belajar dan minat belajar peserta didik terhadap matematika secara signifikan. 


\section{SIMPULAN}

Kegiatan pengabdian masyarakat dilingkungan SD Negeri 14 Pangkalpinang, secara umum mampu melibatkan partisipasi siswa-siswa yang tinggi mulai dari perencanaan hingga pelaksanaannya. Manfaatannyabahwa keberadaan permainan tradisional ini mampu menjadi ruang publik yang menghidupkan kondisi sosial budaya warga dalam berinteraksi baik dengan siswa maupun dengan guru. Pada permainan tradisional ini, kondisi fisik mereka juga tetap dijaga tanpa merubah apapun, sehingga kualitas lingkungan sekolah juga tetap terjaga dan masih dapat ditingkatkan. Dalam pengabdian masyarakat ini, dapat diambil kesimpulan bahwa siswa-siswi SD Negeri 14 Pangkalpinang memiliki semangat belajar dan memainkan permainan caklingking yang baik. Kegiatan pengabdian ini bertujuan untuk memberi pengetahuan kepada siswa/siswi tentang permainan tradisional yakni caklingking.

\section{UCAPAN TERIMA KASIH}

Tim penulis mengucapkan terimakasih atas terlaksananya pengabdian, dan ini di sampaikan kepada: (1) Universitas Muhammadiyah Bangka Belitung melalui LPPM yang telah memberikan hibahpengabdian; (2) Kepala Sekolah, guru-guru dan walikelas di Sekolah SDNegeri 14 Pangkalpinang.

\section{DAFTAR PUSTAKA}

Efendi, D. I. (2015). Permainan Tradisional Sebagai Media Stimulasi Aspek Perkembangan Fisik Motorik Anak Usia Dini. J. Didakt, 13(3), 11-18.

Fajrin, O. R. (2015). Hubungan tingkat penggunaan teknologi mobile gadget dan eksistensi permainan tradisional pada anak sekolah dasar. Jurnal Mahasiswa Sosiologi, 2(6), 1-33.

Handoko, D. , \& Gumantan, A. (2021). Penerapan Permainan Tradisional Dalam Pembelajaran Olahraga di SMAN 1 Baradatu. Journal of Physical Education, 2(1), 1-7. https://doi. org/10. 33365/joupe. v2i1. 951

Hasyim, N. , \& Putri, A. B. U. (2017). Upaya Melestarikan Permainan Tradisional Engklek Melalui Teknologi Digital Interaktif. Jurnal Rupa, 2(2), 122-122. https://doi. org/10. 25124/rupa. v2i2. 1011

Kadir, K. (2008). Mengembangkan norma sosiomatematik (sociomathematical norms) dengan memanfaatkan potensi lokal dalam pembelajaran matematika. Pythagoras: Jurnal Pendidikan Matematika, 4(1).

Kurniawan, M. R. (2016). Analisis Permainan Tradisional Dalam Implementasi Pendidikan Karakter di Sekolah Dasar. Metodik Didaktik, 13(2), 99-105.

Misyanto, M. (2016). Analisis Faktor Penyebab Rendahnya Hasil Belajar Peserta Didik Kelas V pada Mata Pelajaran Matematika. Anterior Jurnal, 15(2), 144150.

Muhsetyo, G. , Krisnadi, E. , \& Wahyuningrum, E. (2014). Pembelajaran matematika SD. Jakarta: Universitas Terbuka.

Nurdiani, S. , Verlia, A. , Pririzki, S. J. , \& Amelia, R. (2020). Konsep Etnomatematika Geometri Dalam Permainan Tradisional Caklingking Khas 
Bangka Belitung. In Proceedings of National Colloquium Research and Community Service, 4. https://doi. org/10. 33019/snppm. v4i0. 2152

Nurhayati, I. (2012). Peran Permainan Tradisional Dalam Pembelajaran Anak Usia Dini (Studi di PAUD Geger Sunten, Desa Suntenjaya). Empowerment: Jurnal Ilmiah Program Studi Pendidikan Luar Sekolah, 1(2), 39-48. https://doi. org/10. 22460/empowerment. v1i2p39-48. 614

Susanto, A. (2013). Teori Belajar dan Pembelajaran di Sekolah Dasar. Jakarta: Kencana.

Syaripuddin, S. (2019). Pemanfaatan Ethonomatika Permainan Engklek Dalam Pembelajaran Matematika. Jurnal MathEducation Nusantara, 2(1), 84-89. https://doi. org/10. 32696/jmn. v2i1. 75

Ulya, H. (2017). Permainan tradisional sebagai media dalam pembelajaran matematika. In Prosiding Seminar Nasional Pendidikan, 6(11), 371-376.

Utami, K. P. (2021). Permainan Tradisional Egrang Tempurung Kelapa Sebagai Latihan Keseimbangan Dinamis Pada Anak. Jurnal Sport Science, 11(1), 7-11. http://dx. doi. org/10. 17977/um057v11i1p7-11

Yosinta, S. I. , Nasirun, H. M. , \& Syam, N. (2016). Meningkatkan Motorik Kasar melalui Permainan Tradisional Lompat Kodok. Jurnal Ilmiah Potensia, 1(1), 57-61. https://doi. org/10. 33369/jip. 1. 1. 57-61

Zayyadi, M. (2019). Etnomatematika Budaya Madura (Budaya Madura dan Matematika). Duta Media Publishing. 